\title{
Ares I-X: First Flight of a New Generation
}

\author{
Stephan R. Davis, Deputy Mission Manager \\ Bruce R. Askins, Project Integration Manager \\ Ares I-X Mission Management Office \\ Marshall Space Flight Center \\ Huntsville, AL 35812
}

\begin{abstract}
Since 2005, NASA's Constellation Program has been designing, building, and testing new launch and space vehicles to carry humans beyond low-Earth orbit (LEO). The Ares Projects at Marshall Space Flight Center (MSFC) in Huntsville, AL, have focused on developing the Ares I crew launch vehicle and Ares V cargo launch vehicle. On October 28, 2009, the first development flight test of the Ares I crew launch vehicle, Ares I-X, lifted off from a launch pad at Kennedy Space Center (KSC) on successful suborbital flight.

Basing exploration launch vehicle designs on Ares I-X data puts NASA one step closer to full-up "test as you fly," a best practice in vehicle design. Although the final Constellation Program architecture is under review, the Ares I-X data and experience in vehicle design and operations can be applied to any launch vehicle.

This paper presents the mission background as well as results and lessons learned from the flight.

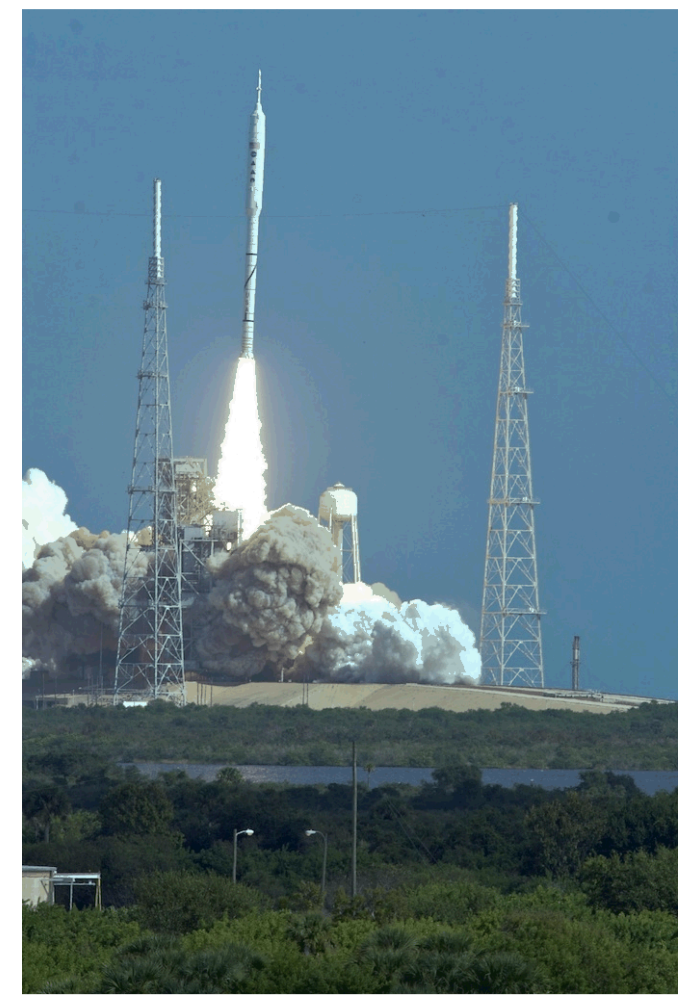

The Ares I is designed to carry up to four astronauts to the International Space Station (ISS). It also can be used with the Ares V cargo launch vehicle for a variety of missions beyond LEO. The Ares I-X development flight test was conceived in 2006 to acquire early engineering and environment data during liftoff, ascent, and first stage recovery. Engineers are using the test flight data to improve the Ares I design before the critical design review - the final review before manufacturing of the flight vehicle begins. The test achieved the following primary objectives:

- Demonstrated control of a dynamically similar, integrated Ares I/Orion, using Ares I relevant ascent control algorithms

- Performed an in-flight separation/staging event between a Ares I-similar First Stage and a representative Upper Stage

- Demonstrated assembly and recovery of a new Ares I-like First Stage element at KSC

- Demonstrated First Stage separation sequencing, and quantify First Stage atmospheric entry dynamics, and parachute performance

- Characterized the magnitude of integrated vehicle roll torque throughout First Stage flight.
\end{abstract}




\section{Introduction}

Since 2005, NASA's Constellation Program has been designing, building, and testing new launch and space vehicles to carry humans beyond low-Earth orbit (LEO), including the Ares I crew launch vehicle and Ares V cargo launch vehicle. Ares I and Ares V are being managed by the Ares Projects at NASA's Marshall Space Flight Center (MSFC) in Huntsville, AL.

Ares I is designed to carry up to four astronauts to the International Space Station (ISS). It also can be launched in tandem with the Ares V cargo launch vehicle to perform a variety of missions beyond LEO. The Ares I-X development flight test was conceived in 2006 to acquire early engineering, operations, and environment data during liftoff, ascent, and first stage recovery for Ares I. The flight test data from Ares I-X will be used to improve the Ares I design before its critical design review in 2011 - the final review before manufacturing of the flight vehicle begins.

\section{Vehicle Elements \& Mission Objectives}

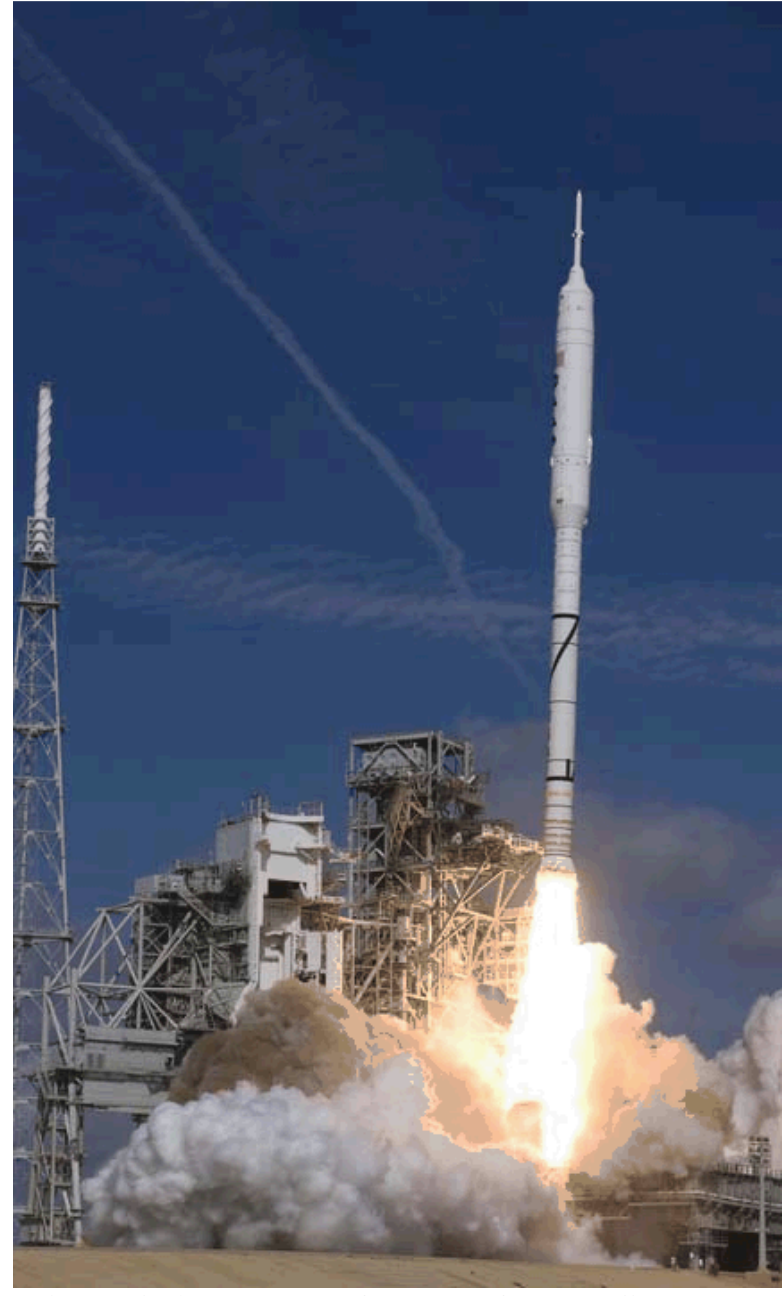

Figure 1. Ares I-X performs a "fly-away" maneuver just after liftoff from Kennedy Space Center's Launch Complex 39B.
The Ares I-X flight test vehicle (FTV) (Figure 1), was not designed to be a full-up space launch vehicle, but rather a development test article for evaluating how the rocket performs from liftoff through first stage separation - a critical part of the flight when the vehicle is subjected to extreme environments. The rocket consisted of a foursegment reusable solid rocket motor (RSRM) from the Space Shuttle inventory with new forward structures and $5^{\text {th }}$ segment simulator to match Ares I, an active roll control system (RoCS), Atlas V avionics, and outer mold line simulators for the upper stage, Orion crew module, and launch abort system.

To build the test vehicle and conduct the flight in such a short timeframe, the flight and ground elements were developed, built, and integrated at multiple NASA centers and companies:

- The first stage, managed at MSFC in Alabama and fabricated at ATK in Utah

- The avionics systems, managed by MSFC and built and tested by a combined Jacobs Engineering/Lockheed Martin team in Alabama and Colorado

- The roll control engines, managed at MSFC and built and tested for Ares I$\mathrm{X}$ at Teledyne Brown Engineering in Huntsville, AL

- The upper stage simulator, built inhouse at Glenn Research Center (GRC) in Ohio

- The crew module/launch abort system (CM/LAS) simulator, built in-house 
and the systems engineering and integration (SE\&I) function was performed at Langley Research Center (LaRC) in Virginia

- The ground systems and operations, performed at Kennedy Space Center (KSC) in Florida.

This part-active, part-simulator vehicle was designed to achieve — and met —all of the following objectives:

- Demonstrate control of a dynamically similar, integrated Ares I/Orion, using Ares I relevant ascent control algorithms

- Perform an in-flight separation/staging event between a Ares I-similar first stage and a representative upper stage

- Demonstrate assembly and recovery of a new Ares I-like first stage element at KSC

- Demonstrate first stage separation sequencing, and quantify first stage atmospheric entry dynamics, and parachute performance

- Characterize magnitude of integrated vehicle roll torque throughout first stage flight

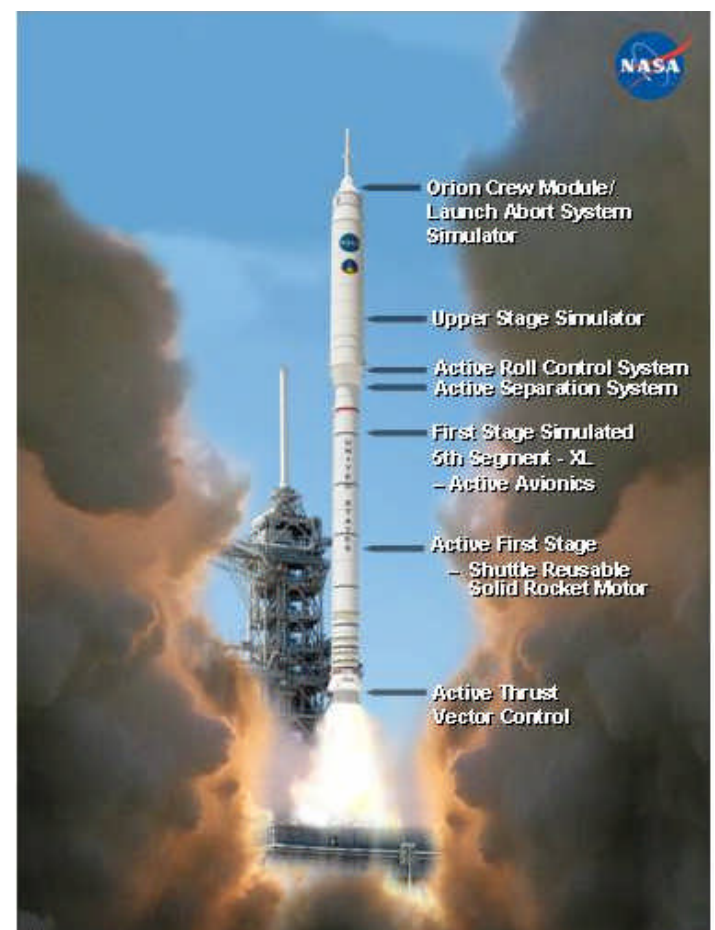

Figure 2. The Ares I-X Flight Test Vehicle incorporates both flight-like and mass simulator hardware.

\section{Vehicle Configuration}

The Ares I-X Flight Test Vehicle (FTV) incorporated a mix of flight and mockup hardware, reflecting a similar length and mass to the operational vehicle (Figure 2). Its four-segment RSRM was modified to include a fifth, spacer segment that made the booster approximately the same size as the five-segment Ares I first stage.

The Ares I-X flight closely approximated flight conditions the Ares I will experience through Mach 4.5, at an altitude of about 130,000 feet and through a maximum dynamic pressure ("Max Q") of approximately 850 pounds per square foot.

The trajectory Ares I-X flew provided aerodynamic, thermal, and acoustic loads sufficient to demonstrate controllability of a dynamically similar vehicle, as required by the first Primary Objective. All these characteristics made the flight test vehicle similar enough to the flight vehicle for aerodynamic comparisons. 


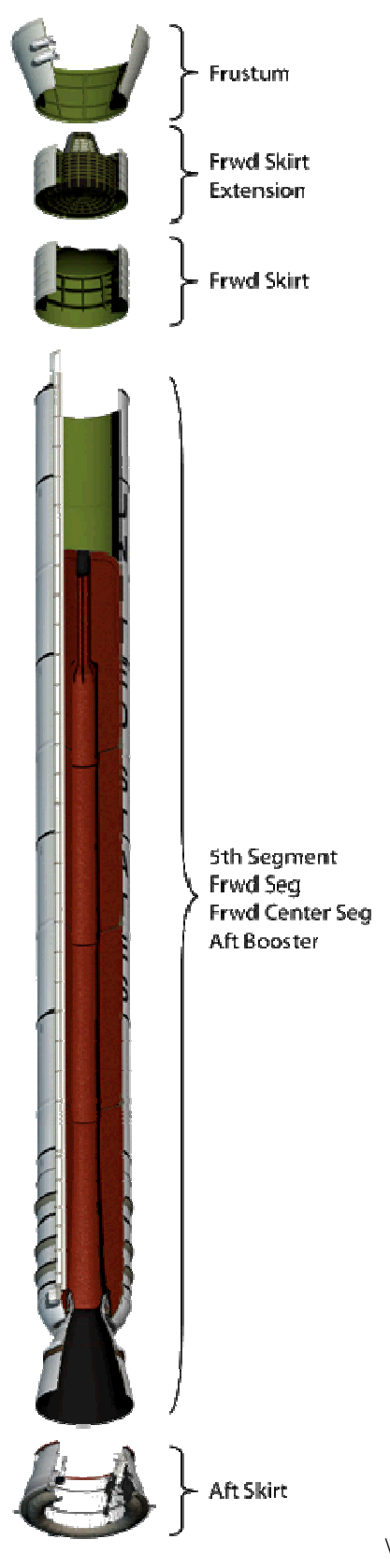

Figure 3. The Ares I-X first stage components included active and simulator hardware.

\section{First Stage (FS)}

Since the FS team used an existing RSRM, most of the work focused on building structures not used for the Space Shuttle but that were needed for the in-line configuration. These included the new forward structures that connect the booster to the Upper Stage Simulator (USS), a fifth spacer segment, which housed the First Stage Avionics Module (FSAM), and a forward skirt, forward skirt extension, and frustum (Figure 3).

Ares I is by no means the first rocket that uses only a solid-propellant first stage, but it can lay claim to being the first such vehicle designed to launch human beings into space. Once a solidpropellant rocket is ignited, it will not shut down until its propellant is consumed. Nevertheless, Ares I was seen as an effective and practical design due to the high safety and reliability of the RSRM, which has been used on more than a hundred Shuttle flights and has been improved over the course of the Shuttle's life.

This is the first human-rated rocket to have such a slender diameter and a wider second stage. Ares I-X demonstrated that a vehicle so designed could be controlled. One of the primary objectives of Ares I-X was to demonstrate that this long, slender vehicle could be launched and controlled throughout its flight.

Ares I-X was the first time the RSRM had been used in an in-line configuration, with the payload stacked atop the booster instead of alongside an external fuel tank, as in Shuttle operations. This created concerns about the effects of thrust oscillation on the rocket, as the vibrations generated by burning first stage propellant matched the resonant frequency of integrated launch vehicle. However, one of the key findings of the flight test was that the magnitude of thrust oscillation was much lower than expected for this flight. 




Figure 4. The Ares I-X first stage and new forward structures stacked in the Vehicle Assembly Building.

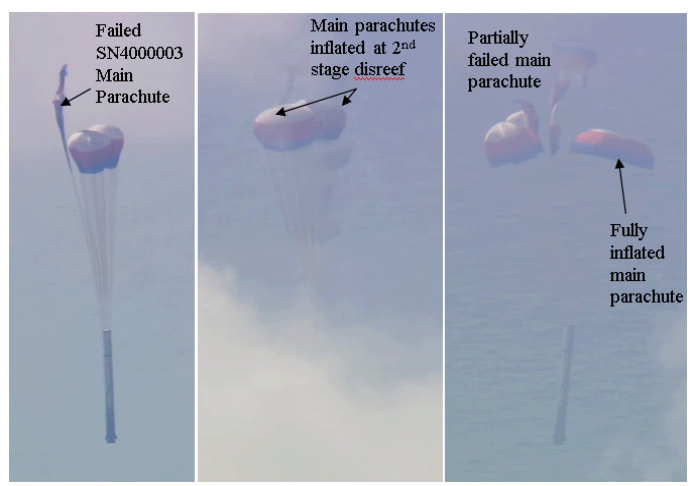

Figure 5a. The Ares I-X first stage coming down for recovery with one of the main chutes failing.
Another concern with using a single RSRM from the Space Shuttle program was balancing and controlling the vehicle using a single propulsion element. NASA's public outreach videos typically liken flying Ares I to "balancing a pencil on the tip of one's finger." Nevertheless, the Shuttle-heritage thrust vector control system - guided by an ascent thrust vector controller box that translated commands from the Atlas avionics - functioned as expected, and control of Ares I-X was nominal.

The flight test also provided a first-time opportunity to stack, integrate, launch, and recover an Ares I-like first stage, which the Ares I-X team did successfully (Figure 4).

The simulated five-segment first stage was heavier than the four-segment booster used for the Space Shuttle, requiring new, larger parachutes to accommodate the additional loads. The main parachutes for Ares I-X were 150 feet across, compared to 136 feet for the Space Shuttle RSRMs. Although drop tests were completed from U.S. Air Force C-17 cargo aircraft at Yuma Proving Ground before the test flight, Ares I-X served as the first operational test of the new parachutes. There was no way to simulate the actual conditions of parachute operations without a full-scale flight test like Ares I-X.

During the recovery process, one main parachute failed and one was damaged when a reefing line was severed early, increasing the loads on the chutes (Figure 5a \& 5b). The remaining main parachute's performance is being characterized to influence the design of the new system.

\footnotetext{
1 “Taking Flight: The Ares I-X Flight Test.” NASA.gov http://www.nasa.gov/exploration/multimedia/index.html.
} 


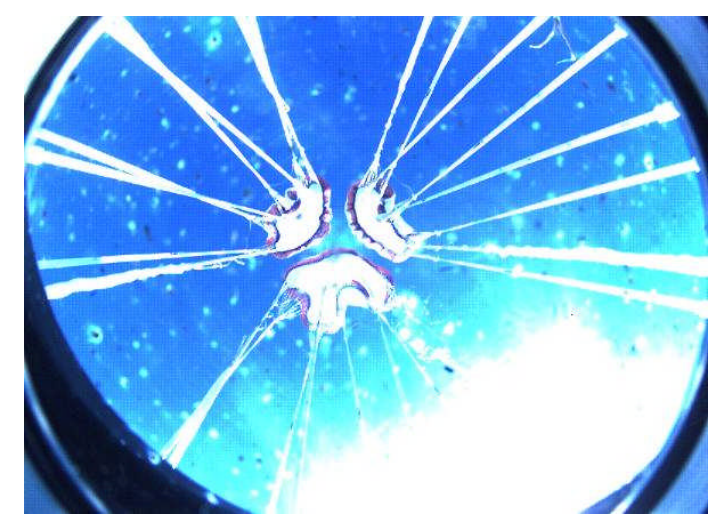

Figure 6b. High-speed cameras captured the severing of the main parachute line.

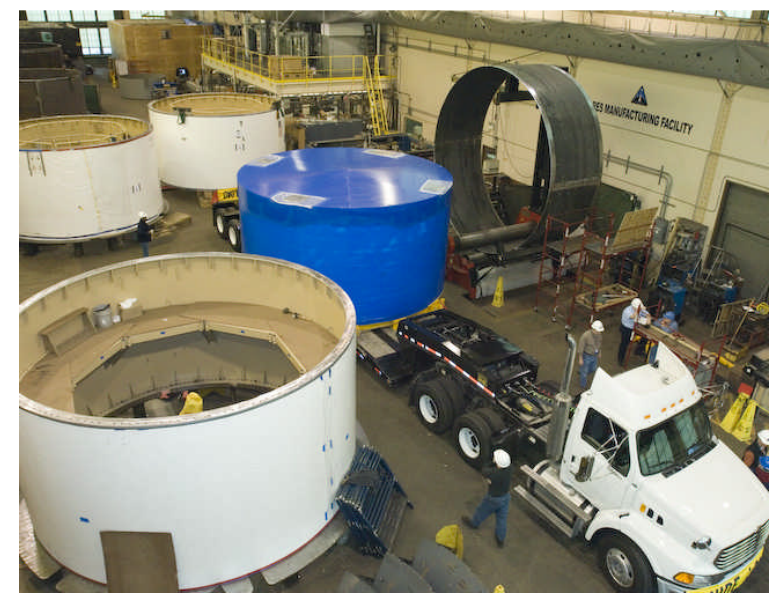

Figure 7. Ares I-X upper stage simulator segments are seen here being fabricated at Glenn Research Center.

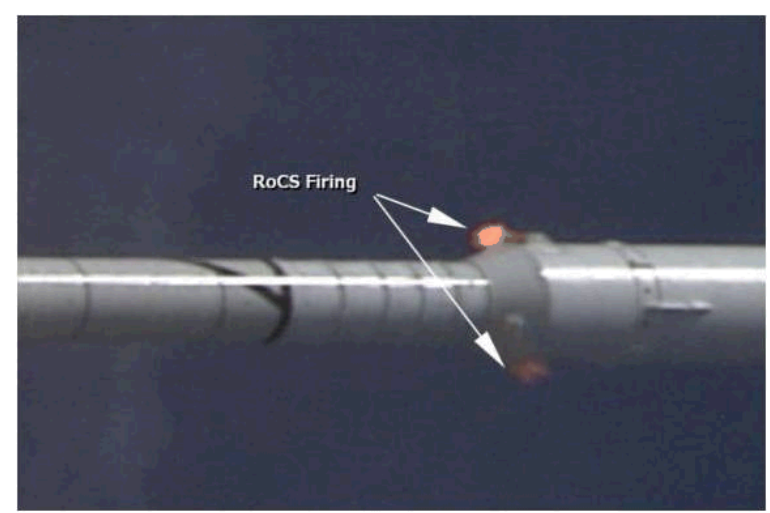

Figure 8. RoCS fired minimally during the flight.
Upper Stage Simulator (USS)

Glenn Research Center in Ohio built the USS in a series of 11 smaller "tuna can" segments (Figure 6). In October 2008, these segments were delivered by truck and barge to KSC where they were stacked and integrated in the Vehicle Assembly Building (VAB). To allow for worker access on the launch pad, each tuna can had a set of platforms and ladders built inside.

Stacking and integration of the USS segments proceeded very smoothly in the VAB. This was especially remarkable considering that fabrication of the USS began before the critical design review had been completed.

After first stage separation, the USS tumbled in what appeared from the ground to be an adverse direction; however, Monte Carlo simulations had predicted such a tumble, so this did not surprise the experts. No recontact was made between the USS and first stage after separation. The USS splashed down after the flight, sinking and was not recovered.

\section{Roll Control System (RoCS)}

NASA engineers were concerned that the rocket would tend to roll around its direction of forward motion due to aerodynamic forces and torque from the first stage. A primary objective of Ares I-X was to measure and counteract this roll using an active roll control system (RoCS, Figure 7). Axial engines harvested from Peacekeeper missiles that were due to be decommissioned were modified and repackaged as part of a new design for the FTV by Teledyne Brown Engineering in Alabama, under management by MSFC. 
After performing a 90-degree orientation roll maneuver following liftoff, he RoCS engines fired only minimally, indicating a minimal amount of roll torque in flight. This was important for confirming that aerodynamically induced roll for this rocket configuration was not an issue. Some had predicted that it would hamper the rocket's stability and subject a crew to unpleasant flight environments.

\section{Avionics}

The Ares I-X avionics hardware used a combination of avionics components from the Atlas $\mathrm{V}$ Evolved Expendable Launch Vehicle (EELV), heritage Space Shuttle systems, off-the-shelf development flight instrumentation (DFI) from several sources, and new hardware designed to translate signals between the Atlas hardware and Shuttle-heritage thrust vector control (TVC) system. The avionics hardware for this flight was not required to be extensible to Ares I; however, the guidance and control algorithm was based on the one planned for Ares I. Testing of the Guidance, Navigation, and Control (GN\&C) algorithms was a primary objective of the Ares I-X flight test. Integration of the avionics was the primary responsibility of Jacobs Technology in Alabama, with Lockheed Martin in Colorado as a major subcontractor.

Avionics integration and full system testing also went very smoothly, partly because of the work done in Lockheed Martin's Systems Integration Laboratory (SIL) facility in Denver, Colorado. The SIL tested flight or flight-like hardware, including vehicle-length cabling to simulate the configuration of the actual vehicle as much as possible. The SIL also stood in remotely for the FTV during launch countdown exercises at KSC prior to the launch. The primary avionics challenges overcome during Ares I-X resulted from procedural conflicts regarding whether to use Atlas or Shuttle-heritage processes, but in the end the avionics functioned effectively, even after a thunderstorm with a near lightening strike on the night before the second day of operations threatened to delay the launch.

The only anomalies with the avionics system occurred with the DFI, where 7 percent of the data was lost from the last 90 seconds of the flight; however, this was not flight-critical information. This loss occurred when the multiplexer (MUX), which stores data in temporary memory and then writes it to permanent memory with a specified file structure, lost power as the vehicle impacted the water and switched to external power. The MUX was not able to properly commit data to permanent memory before the solid-state device lost power resulting in holes in the data during the last 90 seconds. Data from the rest of the flight was captured via the MUX and telemetry and is being analyzed by engineers across NASA.

\section{Command Module/Launch Abort System (CM/LAS) Simulator}

Because Ares I-X was a test of the Ares I launch vehicle only, there was no Orion payload on board. Instead, the CM and LAS were mass simulator hardware built in-house at NASA's Langley Research Center in Virginia then flown by C5 to KSC. Sensors on the forward structures will enable NASA engineers to obtain accurate information about aerodynamic and acoustic loads in a flight environment.

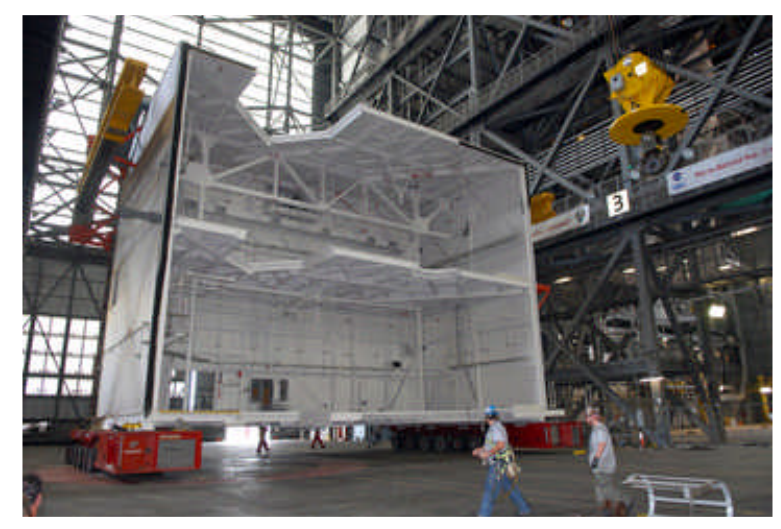

\section{Ground Operations}

In the VAB, several platforms and other structures designed for the Space Shuttle's configuration had to be removed to accommodate the much taller, in-line design of Ares I-X, while other platforms and environmental control systems had to be installed to meet flight test needs (Figure 8).

Vehicle preparation activities resulted in lessons learned for ground operations personnel, including hardware deliveries, cable routing, transferred work 


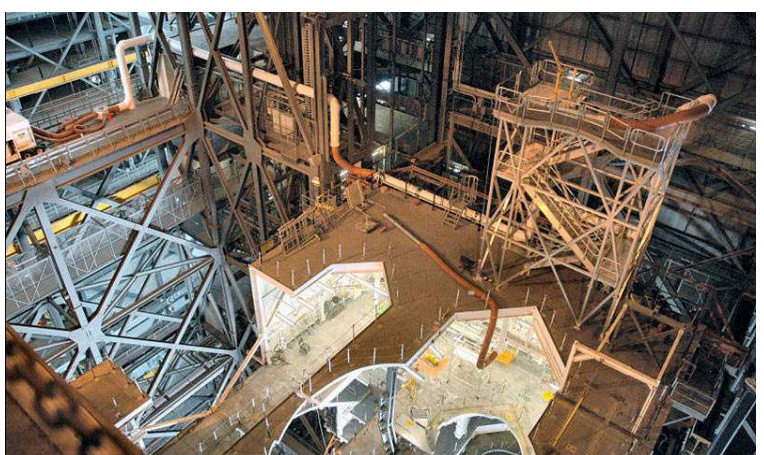

Figure 8. Platform $C$ was removed from the VAB's High Bay 3 (top) and other platforms were added (bottom) to give ground operations staff access to the Ares I-X interstage segment.

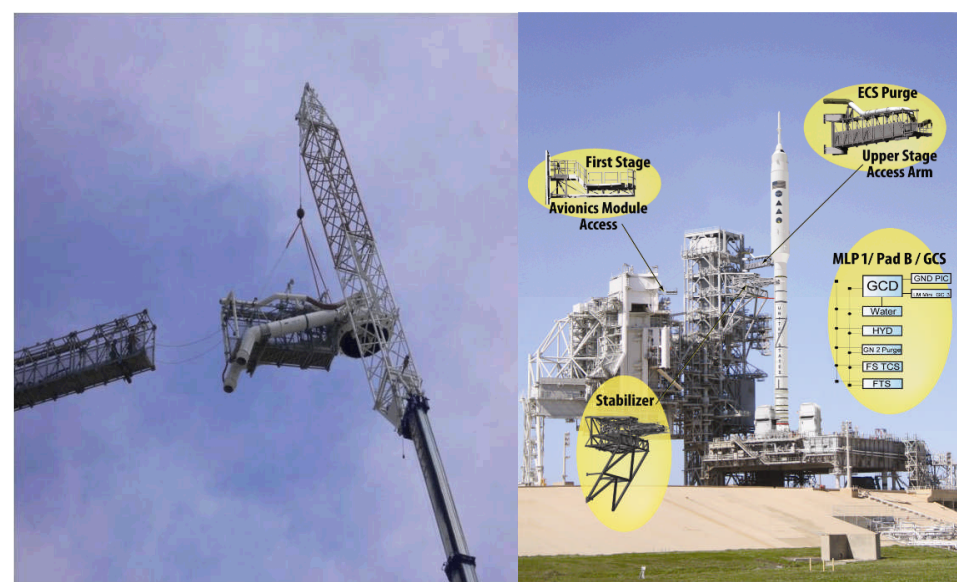

Figure 9. Gaseous oxygen arm being removed (left) and artist's concept (right) depicting hardware added to LC 39B for Ares I$\mathrm{X}$.

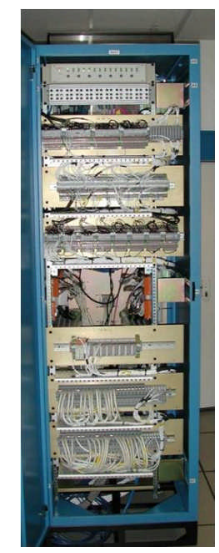

Figure 10. A GC3 rack installed in the Mobile Launcher Platform also is used to control Atlas V.

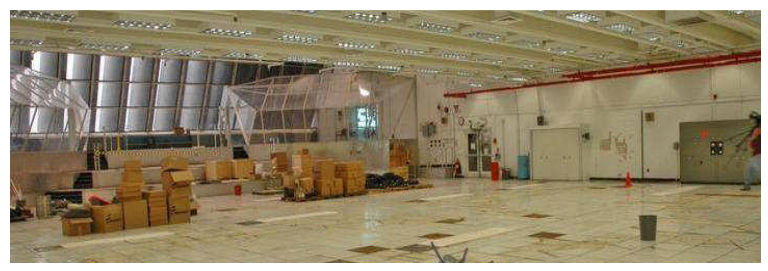

and custodial paperwork.

Ares I-X proved to be a resource challenge, as individuals and ground service equipment (GSE) supporting the mission also were required for Shuttle or Atlas V operations at LC 40/41 at Cape Canaveral Air Force Station. Conflicts over resources may continue to be a challenge for the agency in the next few years, especially if Ares flight tests continue while the Space Shuttle Program is extended.

At LC 39B, several Shuttle-specific access arms were removed (e.g. the gaseous oxygen "cap" usually attached to the top of the external tank) and others were added (the vehicle stabilization system, environmental control system, and access bridge for the first stage avionics module) to accommodate the Ares I-X FTV (Figure 9). However, this work was delayed by resource conflicts, including a launch-on-need backup mission to support the Hubble Space Telescope servicing flight in August 2009.

The ground command, control, and communication (GC3) hardware was incorporated into the Mobile Launcher Platform (MLP). The primary function of the GC3 unit, an Atlas V system provided by Lockheed Martin, was to provide control and data interfaces between the FTV and ground operations during countdown operations (Figure 10).

Perhaps the most dramatic change made to KSC's launch infrastructure was made to the Launch Control Center's Firing Room 1 (Figure 11). Originally used to launch the first Space Shuttle mission, Firing Room 1 received a complete refurbishment of its wiring, 


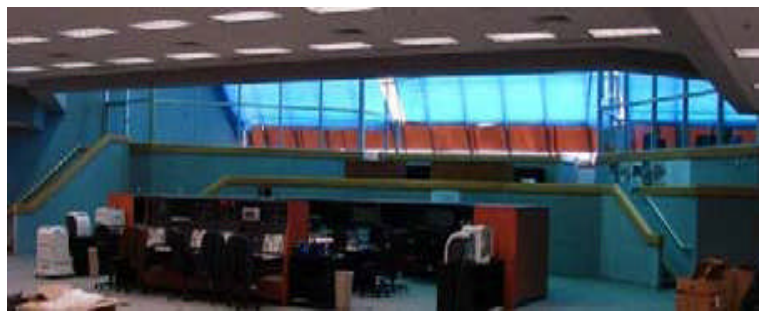

Figure 11. The VAB Launch Control Center's Firing Room 1, before (top) and after (bottom) refurbishment for Ares I-X.

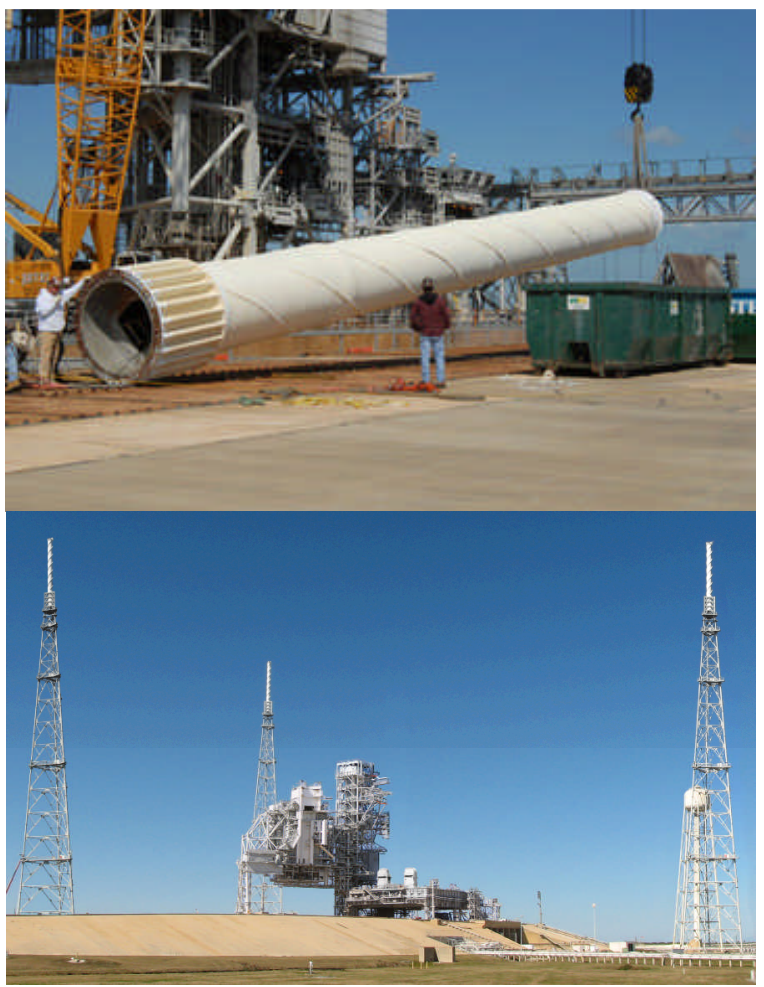

Figure 12. The single lightning mast atop the fixed service structure (FSS) at LC 39B (top) was replaced by a trio of towers (bottom). computer systems, console, and interior fixtures. The entire room was not needed, given the limited scope of Ares I-X, but the firing room is now equipped to support future flight tests and a variety of exploration missions, including those planned for the Constellation Program.

The lightning protection system at LC 39B was replaced by a trio of 600foot-tall towers connected by a catenary wire to account for the much greater height of the Ares vehicles over shuttle (Figure 12). These towers will be kept in place when the rest of the LC 39B service structure is dismantled to make way for the structures needed for the Constellation Program.

The stacking on the MLP of Ares I-X in the VAB went very smoothly, demonstrating the conscientious efforts by the Ares I-X team to keep the vehicle's design and hardware fabrication integrated across multiple NASA centers. The vehicle segments, but also particularly the avionics hardware, fit and functioned together through integrated system testing with minimal rework. Problems were solved by a dedicated trouble-shooting team established on-site at the $\mathrm{VAB}$, with a separate team established to address issues with the over 700 sensors comprising the developmental flight instrumentation (DFI).

Like Shuttle, Ares I-X after being stacked on a MLP rolled out to the pad on an Apollo-era crawlertransporter. Ares I-X was held in place by the four hold-down posts attached to the first stage aft skirt during rollout, and a new vehicle stabilization system (VSS) added to the vertical service structure kept the vehicle from swaying on the pad prior to launch. Both systems proved more than sturdy enough to keep the vehicle vertical. Wind-induced oscillations, even during winds up to 25 knots, did not exceed three inches over the entire length of the 327-foot rocket. The VSS itself, comprising commercial hydraulic struts, was a low-cost design choice made late in the project that proved as effective as a 
proposed support tower built atop the MLP. The use of commercial hardware saved the agency millions of dollars.

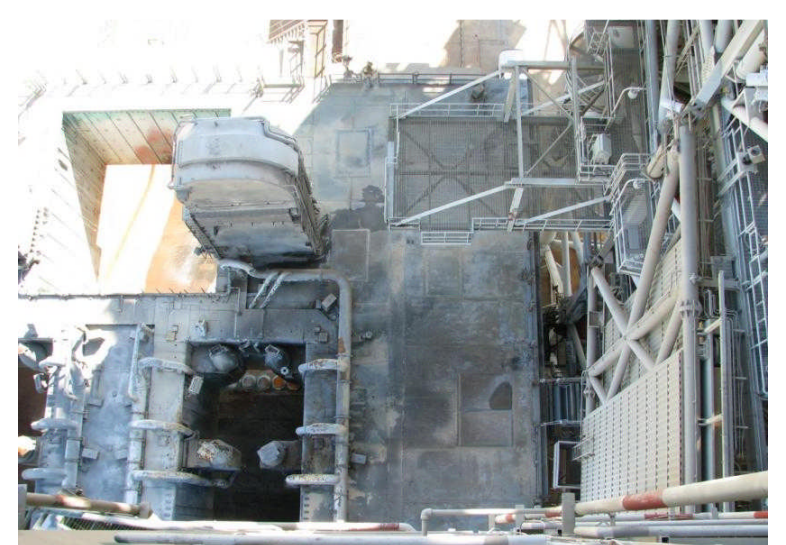

As part of liftoff, Ares I-X performed a "flyaway maneuver," during which the rocket tilted away from Launch Complex 39B's service structure because the Shuttle-era sound suppression system was not designed to support Ares I operations. The plume from the first stage caused more damage to the service structure than is common for a Space Shuttle flight (Figure 13). This information will be useful in designing future launch facilities.

Figure 13. Ares I-X caused more damage to Launch Complex 39B than a Shuttle flight.

One of the most surprising lessons learned during Ares I-X was the launch constraint imposed by triboelectrification, a static-generating condition created by flying through moisture-laden clouds that can interfere with radio signals to and from the vehicle. Triboelectrification can be mitigated most easily by encasing electronics in "Faraday cage" structures that insulate electronics from exterior sources of static and by covering the vehicle in non-static-producing paint. Late in the mission planning, there was some question about whether Ares I-X had paint which was not consistent with triboelectrification requirements on some of its exterior surfaces. Because the mitigation analysis was still in work as the launch day approached, the 4-hour scheduled launch windows in October were constrained by the need for nearly cloud-free skies. Ares I-X launched on the second day's attempt. On the first launch day, there were multiple windows, but the flight failed to meet triboelectrification requirements. Future Ares vehicles will address this issue earlier in the requirements process.

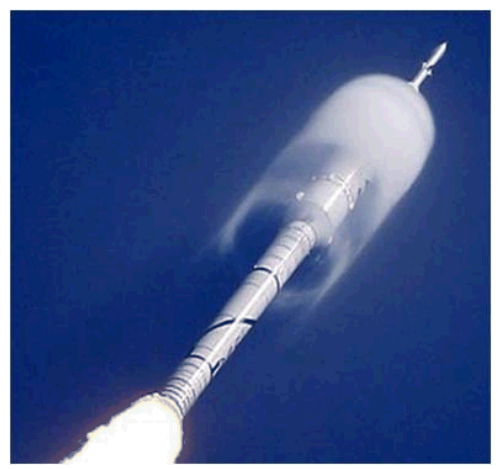

Figure 14. Ares I-X in flight.

\section{Summary}

The Ares I-X suborbital development flight test demonstrated NASA's ability to design, develop, launch and control a new human-rated launch vehicle (Figure 14). This hands-on missions experience will provide the agency with necessary skills and insights regardless of the future direction of space exploration. The Ares I-X team, having executed a successful launch, will now focus on analyzing the flight data and extracting lessons learned that will be used to support the development of future vehicles. 


$\begin{array}{ll}\text { Nomenclature } \\ \text { BDM } & \text { Booster Deceleration Motor } \\ \text { CM } & \text { Crew Module } \\ \text { DFI } & \text { Developmental Flight Instrumentation } \\ \text { EELV } & \text { Evolved Expendable Launch Vehicle } \\ \text { FS } & \text { First Stage } \\ \text { FTV } & \text { Flight Test Vehicle } \\ \text { GC3 } & \text { Ground Command, Control, and Communication } \\ \text { GN\&C } & \text { Guidance, Navigation, and Control } \\ \text { GRC } & \text { Glenn Research Center } \\ \text { ISS } & \text { International Space Station } \\ \text { JSC } & \text { Johnson Space Center } \\ \text { KSC } & \text { Kennedy Space Center } \\ \text { LaRC } & \text { Langley Research Center } \\ \text { LAS } & \text { Launch Abort System } \\ \text { LEO } & \text { Low-Earth Orbit } \\ \text { LH } & \text { Liquid Hydrogen } \\ \text { LOX } & \text { Liquid Oxygen } \\ \text { MLP } & \text { Mobile Launcher Platform } \\ \text { MMO } & \text { Mission Management Office } \\ \text { MSFC } & \text { Marshall Space Flight Center } \\ \text { NASA } & \text { National Aeronautics and Space Administration } \\ \text { RoCS } & \text { Roll Control System } \\ \text { SE\&I } & \text { Systems Engineering and Integration } \\ \text { SIL } & \text { Systems Integration Laboratory } \\ \text { SRB } & \text { Solid Rocket Booster } \\ \text { TVC } & \text { Thrust Vector Control } \\ \text { USS } & \text { Upper Stage Simulator } \\ & \end{array}$

American Institute of Aeronautics and Astronautics 